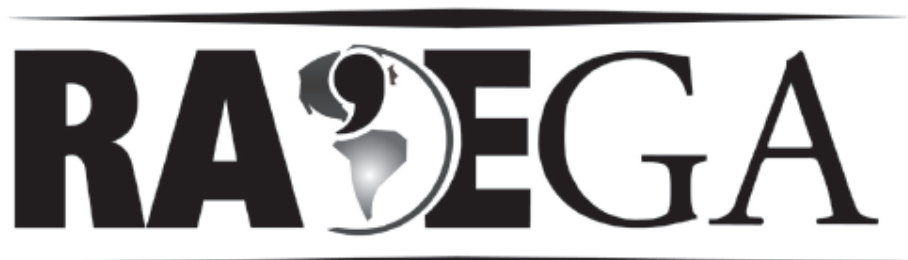

O ESPAÇO GEOGRÁFICO EM ANÁLISE

\title{
A CIDADE VERDE, IMAGENS E DISCURSOS: O CASO DE MARINGÁ (PR) BRASIL
}

\section{A CIDADE VERDE, IMAGES AND DISCOURSES: THE CASE OF MARINGÁ (PR) BRAZIL}

\author{
Marcos Clair Bovo ${ }^{1}$ \\ Margarete Cristiane de Costa Trindade Amorim²
}

\section{RESUMO}

A presente pesquisa tem como propósito/intenção apresentar uma breve reflexão referente à imagem da "cidade verde" que predomina no município de Maringá-PR, destacando a concepção de cidade jardim, as imagens e os discursos que vinculam na mídia, seguidas das principais propostas implantadas no município referente à legislação ambiental. Desta forma buscamos investigar a ação do marketing "Maringá Cidade Verde", por meio das propagandas, reportagens de revistas de circulação nacional, e dos discursos vinculados pelo poder público referente à imagem e a forma urbana dos projetos que estimulam a valorização imobiliária da cidade de Maringá. As imagens produzidas aparecem com intencionalidades específicas utilizando principalmente suas áreas verdes como ícones de divulgação, ou seja, os parques, as praças e suas amplas ruas arborizadas como sinônimo de qualidade ambiental.

Palavras chave: Imagem; ambiente urbano; Cidade Verde; Maringá.

\footnotetext{
${ }^{1}$ Professor Adjunto do Departamento de Geografia da Universidade Estadual do Paraná - Campus de Campo Mourão. Doutor em Geografia pela Universidade Estadual Paulista - Campus Presidente Prudente - Líder do Grupo de Estudos Urbanos da Fecilcam (GEURF) - E-mail mcbovo@yahoo.com

2 Professora Doutora do Departamento de Geografia - Faculdade de Ciência e Tecnologia - Campus Prudente - Rua Roberto Simonsen, 305 - Tel. (18) 32295375 - FAX (18) 32218212 - CEP. 19060.900 Presidente Prudente-SP. E-mail mccta@fct.unesp.br
} 


\begin{abstract}
This research aims at presenting a brief reflection concerning the "cidade verde" image that predominates in the city of Maringá-PR, highlighting the conception of garden-city, the images and discourses that convey in the media, followed by the main proposals implanted in the city referring to environmental law. Thus we try to investigate the action of the marketing speech "Maringá Cidade Verde" through advertisements, national circulation magazine's articles, and the discourses conveyed by public power concerning the image and urban form of projects which stimulate the estate valuation in Maringá. Such images appear with specific intentions, using mainly the city's green areas as icons of propagation: parks, squares and large leafy streets, as a synonym of environmental quality.
\end{abstract}

Keywords: Image; urban environment; Cidade Verde; Maringá.

\title{
1. Introdução
}

O discurso ecológico está diretamente implícito na produção do espaço urbano. Através dele, a cidade torna-se agradável do ponto de vista estético. Entretanto, as preocupações das contradições do capital e do trabalho ficam em segundo plano. No primeiro plano, a causa ecológica pode parecer neutra e desprovida de qualquer poder ideológico ou manifestação de classes. Porém, a produção e divulgação dos discursos ligados à ecologia não são neutros; ao contrário, são ideológicos e representam interesses da classe dominante. Isso que fica evidente quando Maringá divulgou o cognome "Cidade Verde". Esse discurso procurou homogeneizar os "olhares" para a cidade tentando, com isso, ocultar as contradições no modelo de produção do espaço urbano maringaense.

Nesta pesquisa, optou-se por relacionar a imagem de Maringá transmitida pelo poder público e pela mídia a partir da década de 1980. Nesta década foram desenvolvidos vários projetos no município relacionados com o paisagismo e urbanismo e também a árvore se tornou o símbolo de preservação ambiental, pois o slogan "cidade canção" já era ultrapassado e nada trazia de benefício para a cidade. 
Neste sentido, Paula (1998) afirma que Maringá necessitava de algo que remetesse à idéia de preservação ambiental, de ecologia, de qualidade de vida e beleza urbana, e acima de tudo, de um signo memorial capaz de trazer em si uma carga representativa de relações passadas e presentes com a natureza, e que tivesse uma linguagem universal.

É com essa idéia de natureza preservada, que a árvore torna-se símbolo de Maringá e o discurso vai sendo difundido entre a população maringaense. $O$ verde está presente nas ruas, avenidas, praças e parques. Esse imaginário não é algo totalmente alienante, visto que a população usufrui desse imaginário em seu favor. Entretanto, em determinados momentos, esse imaginário acaba seduzindo seus moradores e visitantes, que assim se alienam da realidade ali existente.

É neste contexto, que a presente pesquisa tem por objetivo apresentar uma análise das propagandas veiculadas na mídia e do discurso promotor da imagem e da forma urbana, dos projetos que estimulam a valorização imobiliária, e, sobretudo a segregação urbana inerente no processo de expansão da cidade, reiterando o discurso voltado para o investimento empresarial.

A presente pesquisa foi desenvolvida através de levantamento bibliográfico em teses, dissertações e livros, artigos, revistas, folder referentes à imagem de cidade verde.

\section{A Formação Histórica de Maringá e o Planejamento Urbano da Cidade Jardim}

Maringá está localizada no Norte do Paraná, entre as coordenadas

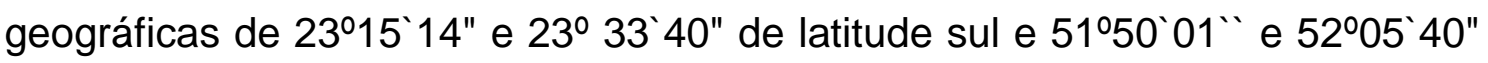
de longitude oeste, limitando-se ao norte com os municípios de Ângulo e Mandaguaçu, ao sul com os municípios de Floresta, Ivatuba e Marialva, a leste com os municípios de Sarandi e Marialva, a oeste com os municípios de Paiçandu e Mandaguaçu e a noroeste com os municípios de Astorga e Iguaraçu (Figura 01). Sua superfície é de $473.064 .190 \mathrm{~m}^{2}$, sua altitude média é 
de 545 metros e encontra-se na região fisiográfica chamada de Terceiro Planalto Paranaense.

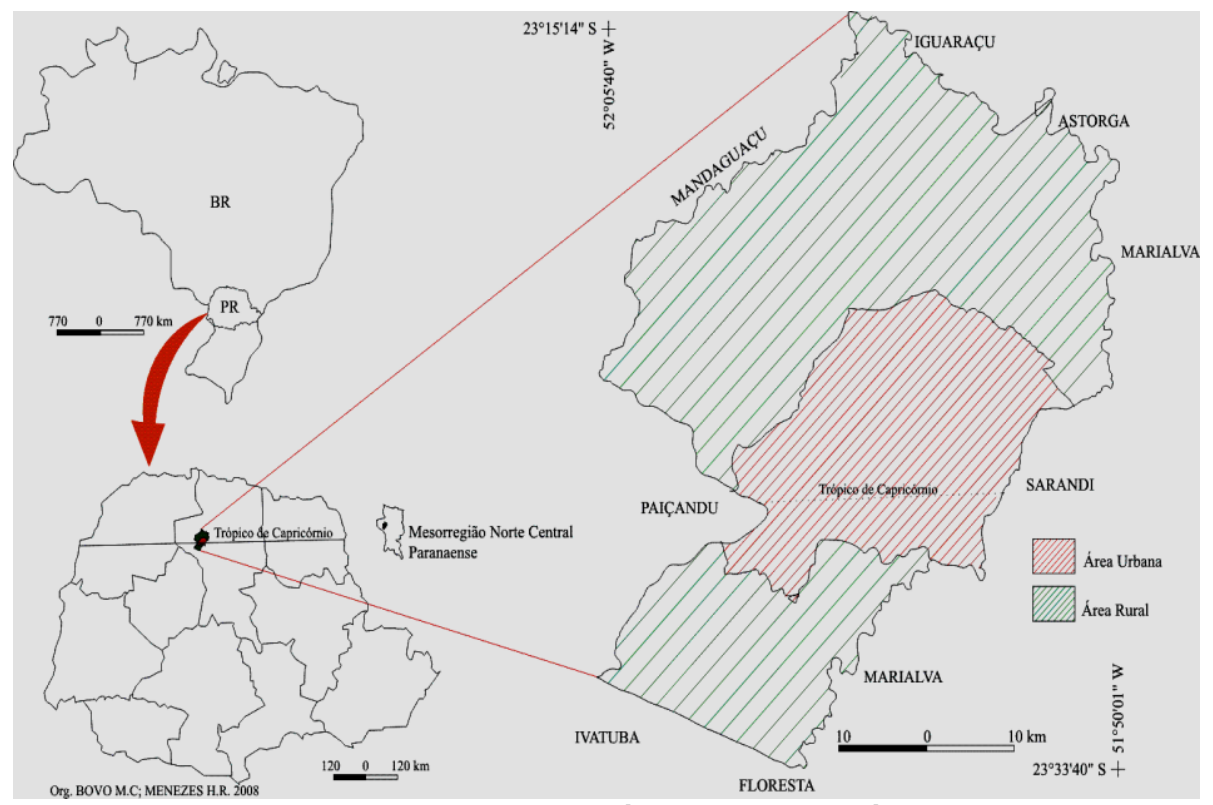

Figura 1: Localização do município de Maringá.

Fonte: Org. BOVO, M.C; MENEZES H.R.2008.

A história de Maringá inicia-se com a vinda dos primeiros fazendeiros paulistas e mineiros em princípios do século $\mathrm{XX}$, os quais tinham como objetivo desbravar novas terras para o plantio de café. É neste contexto, que a empresa colonizadora britânica Paraná Plantations Company, através de sua subsidiária, a Companhia Melhoramentos Norte do Paraná, adquiriu do Governo do Estado do Paraná e de diversos posseiros uma gleba de 515.000 alqueires, que constituíam o Norte Novo do Paraná (GARCIA, 2006, p. 25).

A cultura de café viabilizou o desenvolvimento da região, contribuindo para sua forte divulgação em todo o país, tornando-se necessário dar início ao processo de colonização a fim de vender os lotes. Para Negri (2006), os lotes foram vendidos a preços baixos, e, além disso, a Companhia tinha como propósito garantir o desenvolvimento das cidades, então, doava terrenos urbanos para o poder público e para outras repartições ali se instalarem. Para o autor supracitado, "a mercantilização da economia nacional aliada à acumulação de capitais produtivos e comerciais oriundos do café aprofundara a 
divisão técnica do trabalho no campo e nas cidades cedendo espaço para novos tipos de capital, o industrial e bancário" (NEGRI, 2001, p. 28).

Para Heidecke (2001, p. 34), “A própria política da companhia colonizadora estabelecia que devesse favorecer-se e dar apoio aos fazendeiros, sem por isso deixar de levar em consideração àqueles que dispunham menores recursos".

Desta forma, a Companhia iniciou o processo de colonização fundando a cidade de Londrina, tendo como objetivo a demarcação de lotes urbanos e rurais. Os lotes rurais eram de pequenas dimensões, variando entre 10, 15 e 20 alqueires, o que promovia uma reforma agrária voltada para a pequena propriedade, destinada a fortalecer as relações comerciais das cidades fundadas na própria região em decorrência do pequeno volume de produção proveniente dos produtores rurais, deixando-os inviabilizados de comercializar o montante recolhido nos grandes centros, conforme afirmam Carvalho e Mendes (1999).

Paralelamente aos loteamentos rurais, os lotes urbanos surgiam como uma proposta de fundar cidades com o objetivo de prestar serviços à população rural. Desta forma, o posicionamento dessas cidades obedeceu a dois critérios gerais: acompanhar a linha férrea, no caso das cidades de maior importância, ou as estradas de rodagem, quando não houvesse ferrovia, devendo situar-se sempre no espigão.

Assim, através de um planejamento minucioso a Companhia planejou uma série de assentamentos urbanos menores, que teriam uma distância ideal, com o objetivo de facilitar a vida nas propriedades rurais das proximidades, já que os moradores das áreas rurais poderiam deslocar-se a pé até esses centros com uma caminhada de 5 a 9 quilômetros no máximo. Seguindo essa proposta da companhia, Londrina, Maringá, Cianorte e Umuarama foram estrategicamente implantadas ao longo da ferrovia, com intervalos regulares, e foram desenhadas por engenheiros e agrimensores.

Diante da proposta que Ihe foi apresentada a Companhia encarregou de elaborar o projeto de Maringá o engenheiro Jorge de Macedo Vieira, que trabalhava na Companhia City de Loteamentos, em São Paulo, no mesmo 
período em que Barry Parker desenvolveu os projetos dessa empresa para os bairros paulistanos Jardim América, Alto da Lapa e Pacaembu. A título de informação, Parker era sócio de Raymond Unwin e juntos haviam desenhado as primeiras cidades-jardins inglesas. Desta forma, Jorge Macedo Vieira foi impulsionado e influenciado pela "arte inglesa de projetar cidades" e muitas de suas ideias e soluções foram aplicadas no anteprojeto de Maringá, com base no tratado de desenho urbano de Unwin, publicado em 1999, conforme afirma Rego (2001).

O desenho de Vieira para Maringá em 1947 era constituído de uma cidade com mais de 400 quadras (Figura 2), projeto considerado muito ambicioso na época, indo muito além de Londrina. A proposta inicial partiu de três pontos fundamentais: o traçado da linha férrea no sentido leste-oeste e dois pequenos vales ao sul. Estes vales foram destinados a parques urbanos, preservando-se as duas nascentes existentes, eles configurariam o centro da vida comunitária em área plana, todo esse planejamento estava de acordo com as diretrizes propostas por Unwin (1984).

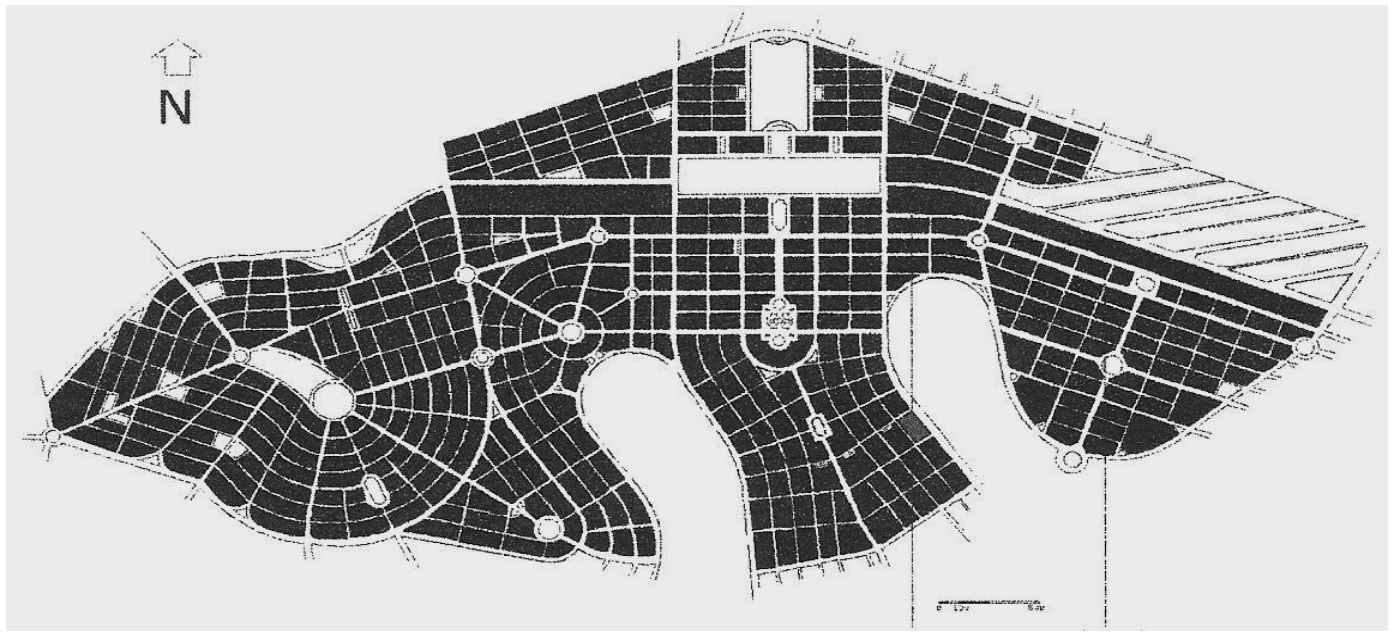

Figura 2: Planta de Maringá elaborada a partir do anteprojeto de Jorge Macedo Vieira Fonte: REGO, Renato Leão (2001).

Segundo Rego (2001), as curvas de nível foram determinantes para o desenho da cidade, pois levou em consideração a configuração topográfica do terreno, definindo a forma urbana alongada e o traçado orgânico como diretrizes para as principais vias. Foi neste contexto que Jorge Macedo Vieira observou as condições naturais e realizou em seu projeto traçados de forma 
irregular na maior parte da malha urbana, contribuindo dessa forma para a implantação das primeiras áreas verdes urbanas do município de Maringá.

Toda essa demarcação teve como finalidade destacar a importância do espaço público, o formalismo, a monumentalidade, de modo a garantir o "caráter artístico" do desenho urbano. Também é possível observar o quadrilátero formado pela ferrovia ao norte e os bosques a leste e oeste, que delimitam a área central de traçado regular, seguido do centro cívico ao lado da estação ferroviária.

Para Rego (2001), no anteprojeto de Vieira as vias que deixam o centro e seguem nas direções sul e oeste da cidade perdem a regularidade ortogonal e adquirem um traçado consoante com as curvas de nível. Já na parte leste as condições do sítio e de seus limites são dadas pela ferrovia e pelo bosque, onde o traçado ortogonal ainda prevalece, com vias curtas e a presença de praças e lotes destinados a edifícios públicos. Na porção norte da linha férrea encontram-se o bairro residencial e o campo de esportes ligados por vias formando um semicírculo.

Em seu anteprojeto Jorge Macedo Vieira dividiu a cidade em três zonas residenciais (principal, popular e operária), zona comercial (dependências e armazéns da estrada de ferro) e os núcleos comerciais, todas sempre com um limite preciso, neste caso, uma avenida ou bosque. Desta forma cada zona ou bairro residencial deveria ter seu centro secundário, constituído de espaço livre público cercado de edifícios comerciais. Neste sentido, o desenho da cidade mostra uma estrutura polinuclear, articulada em uma hierarquia muito clara entre o elemento principal do plano e seus centros secundários, conforme afirma Rego (2001).

Desta forma tanto Maringá como as demais cidades fundadas pela Companhia Melhoramentos Norte do Paraná seguiram o seu plano urbanístico estabelecido, com praças, ruas e avenidas demarcadas segundo a topografia do sítio escolhido, revelando a preocupação no que se refere às áreas verdes e à vegetação nativa.

Com todos esses traços urbanísticos de uma cidade-jardim, seguindo as características contemporâneas, surge Maringá, a 10 de maio de 1947, como 
distrito de Mandaguari. Nesse período Maringá foi denominada de "Cidade Fantasma". "Esta denominação era consequência de uma cláusula nos contratos da Companhia que só vendia lotes de terras no perímetro urbano com a obrigação do adquirente construir em determinado prazo" (ESTRADA, 1962, p. 27).

Maringá tornou-se município através da Lei $n . \stackrel{0}{790}$, de 14 de fevereiro de 1951, com os distritos de Iguatemi, Floriano e Ivatuba (hoje emancipada). No dia 09 de março de 1954 foi instalada a Comarca de Maringá. A cidade foi projetada por Jorge Macedo Vieira para abrigar uma população de 200.000 habitantes em um prazo de 50 anos, porém Maringá superou esta expectativa, contando hoje com 325.968 habitantes (PMM, 2008).

O conceito de cidade-jardim de Ebenezer Howard foi seguido de forma detalhada por Jorge Macedo Viera no traçado de Maringá, no qual buscava uma organicidade a adequação do espaço urbano através das características da paisagem local e da presença de extensos parques e lugares públicos amplos e abertos, buscando o respeito às imposições da topografia local e a proteção dos mananciais. Isso se verifica pelos três parques, com um sistema viário de muito pouca declividade e bastante amplo, constituído de notável arborização (figura 03), o que acabou conferindo à cidade uma originalidade única dentro do contexto urbanístico brasileiro.

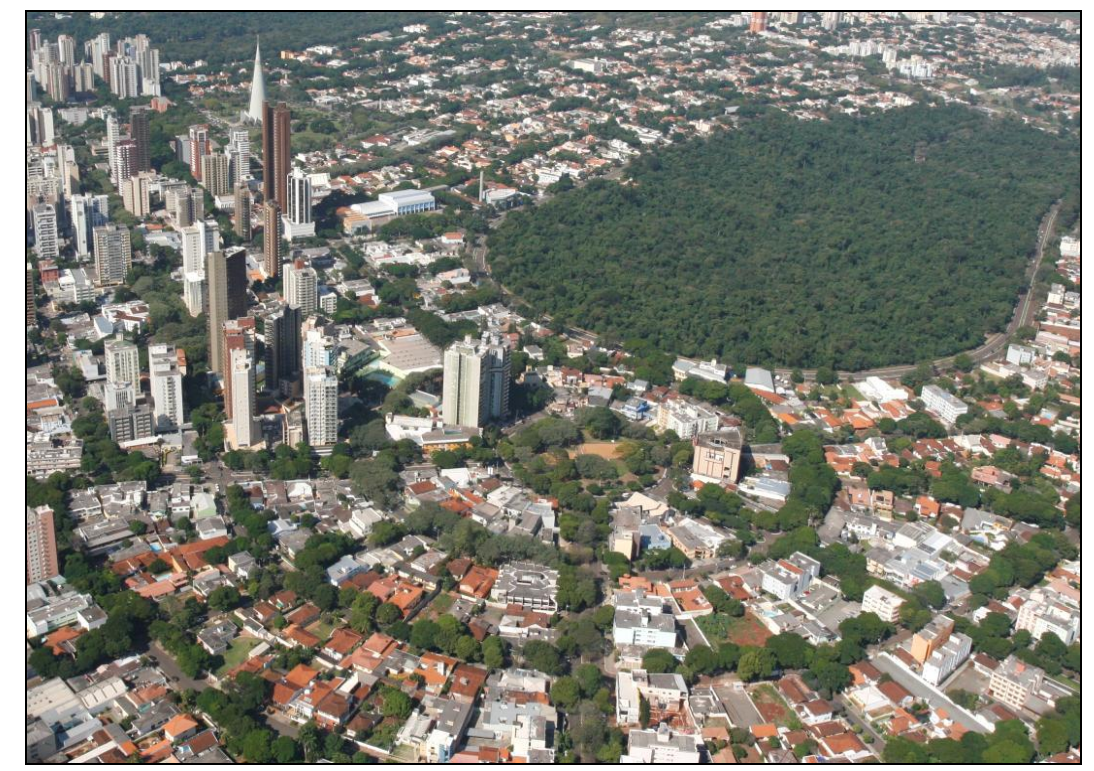

Figura 03: Vista panorâmica de Maringá.

Foto: Prefeitura Municipal de Maringá - Galeria de fotos 2010. 
Com o passar dos anos e seu processo evolutivo, esse modelo de desenho urbano não se repetiu na expansão da malha urbana de Maringá. 0 que se percebe é que o traçado original de Maringá vem se descaracterizando, com uma perda crescente da qualidade em função da expansão recente, sem ao menos considerar questões importantes do planejamento urbano previstas no plano inicial.

Hoje Maringá, através da sua evolução e expansão territorial, assumiu um monótono traçado ortogonal, contradizendo os princípios da cidade-jardim. Reduziram-se em muito as praças e os espaços abertos, sua organicidade e funcionalidade se perderam, comprometendo os cursos d’água, a manutenção da cobertura vegetal original a manutenção de um adequado padrão de qualidade ambiental.

\section{A Imagem e o Discurso da Cidade Verde}

Para iniciarmos essa discussão será necessário fazer uma breve reflexão em torno do marketing que contribui para as transformações da imagem difundida pela mídia. As imagens produzidas pelos diversos meios de comunicação extrapolam fronteiras e lugares, convertendo o mundo em imagem do mundo, ao mesmo tempo em que a imagem passou a representar um produto em si (BAUDRILLARD, 1995).

É neste contexto que os objetos geográficos apresentam uma intencionalidade nunca vista, em virtude da imposição das determinações da racionalidade técnica sobre os lugares. Para Santos (1996, p.101-102), o espaço não é apenas um receptáculo na história, mas a condição de sua realização qualificada, e essa dialética concreta inclui a ideologia e os símbolos, pois a ideologia produz símbolos, que foram criados para fazer parte do real e que frequentemente tomam a forma de objetos. O real está cada vez mais vinculado à produção da imagem, cuja referência não é apenas abstrata, mas possui relações concretas com o espaço socialmente construído.

Nesta perspectiva é importante destacar que o meio técnico-científicoinformacional, concentrado nas cidades permite a ação da racionalidade técnica sobre os processos simbólicos, intermediando a imagem da cidade. Os 
processos simbólicos envolvidos na produção da imagem da cidade estão cada vez mais concentrados no "meio" e não no "sujeito". A construção da imagem da cidade constitui um processo social de planejamento pelo Estado em favor dos agentes do mercado.

Para Ribeiro (1996) e Garcia (1996), a imagem da cidade foi institucionalizada tendo o citymarketing como destaque. $\mathrm{O}$ citymarketing aparece como um processo que orienta a política urbana e as necessidades do consumidor enquanto investidor, turista ou morador. A promoção da cidade adquire uma importância fundamental na gestão urbana, pois contribui com o planejamento da base infraestrutural do espaço urbano.

Desta forma a projeção de imagens urbanas desejáveis mediante a intervenção no ambiente construído e a renovação de seus aspectos faz parte do denominado marketing de imagem. A meta do marketing de imagem é manipular padrões de comportamento do público alvo para que compre produtos e entretenimento e se associe as organizações, do que é exemplo a cidade de Curitiba, que na década de 1970 buscou renovar os transportes, as áreas históricas e o planejamento ambiental.

Os estudos urbanos da Geografia contemporânea apontam a necessidade de refletir a integração entre a materialidade, a representação e a imaginação. Nesta relação cabe destacar as práticas espaciais e suas categorias de representação do espaço e espaço das representações, como destaca Lefébvre (1991).

Para Ribeiro (1991), a produção da imagem urbana está vinculada ao sistema de produção de imagens e sua configuração como indústria e ideologia na sociedade global. Desta forma as imagens produzidas representam sínteses históricas dos interesses sociais que disputam à interpretação sintética e hegemônica do espaço da vida coletiva. O poder de comando das cidades é exercido pela presença dos setores econômicos e políticos diretamente envolvidos com a apropriação financeira do espaço urbano, conforme afirmam Ribeiro (1988); Harvey (1994); Santos (1996).

O cognome "Cidade Verde" ou "Cidade Ecológica" ressurge com a necessidade de o poder público municipal afirmar o compromisso com a causa 
ecológica, já que a Constituição da República Federativa do Brasil (1988, p. 99), em seu artigo 225, estabelece que: "Todos têm direito ao meio ambiente ecologicamente equilibrado, bem de uso comum do povo e essencial à sadia qualidade de vida". Neste contexto, o Poder Público apropriou-se do marketing "Cidade Verde", o qual coloca a cidade de Maringá como uma das cidades brasileiras que mais investiram na qualidade de vida de sua população.

A partir desse discurso as ações do Poder Público municipal foram orientadas no sentido de afirmar a imagem e transformá-la em símbolo da administração municipal. Essa imagem da cidade de Maringá foi lançada em forma de discurso, como estratégia política. Neste sentido, como ressalta Certeau, "O discurso produz então efeitos, não objetos... fazer crer é fazer" (1994, p.154). Para Certeau, fazer crer é dever do marketing, que procura, a partir de técnicas específicas, cristalizar e divulgar a imagem positiva da cidade. No caso de Maringá podemos constatar a afirmação dessa imagem num cartão postal ou folder, por exemplo, "Maringá, 50 anos - Um Mergulho no Paraíso Verde” (RCA-Vídeos Produções, 1997); "A Realidade em Concreto é Verde" (folheto-PMM); "Conheça Maringá, A Cidade Verde" (Folder-PMM) ou em jornais. Todos esses anúncios afirmam a condição ecológica de Maringá como uma das características que a diferenciam das cidades brasileiras. Os anúncios e reportagens, afirmam que o conforto ambiental em preservar o verde é meta dos administradores.

O discurso ecológico foi muito discutido pelos sanitaristas, pois procura disciplinar e naturalizar os problemas da cidade, como afirma Carlos:

O discurso ecológico apresenta uma concepção idealizada na natureza contraposta à cidade e inventando o antiurbano. Isso vem acalmar. Como processo de reprodução do espaço urbano, fundamentalmente nas metrópoles, tem quase eliminado às áreas vazias e esgotando o processo de verticalização, os empreendedores imobiliários vêm sendo cada vez mais obrigados a limitarem suas ações às áreas periféricas à mancha urbana, com isso tem surgido o "subúrbio jardim", o loteamento de alto luxo. Como convencer a população de alta renda a abandonar a metrópole, aumentar seus custos e tempo de deslocamento, bem como seus gastos para a manutenção das residências? 'Vendendo o Verde'. Criando a necessidade do consumo de espaços verdes, de uma vista saudável longe da poluição e embolsando lucros fantásticos, pois as terras adquiridas de agricultores e 
proprietários rurais por hectares, para em seguida, para serem loteadas e vendidas por $\mathrm{m}^{2}$ (1994, p. 77 ).

A citação anterior remete à ideia e reflexão a respeito do discurso ecológico e da produção do espaço urbano. No tocante à ecologia e à cidade, tal discurso procura transformar esse espaço em um ambiente agradável do ponto de vista estético, o que faz com que as preocupações das contradições do capital e do trabalho fiquem em segundo plano. Num primeiro instante a causa ecológica pode parecer neutra e desprovida de qualquer poder ideológico ou manifestação de classes; porém a produção e divulgação dos discursos ligados à ecologia não são neutros, ao contrário, são ideológicos e representam interesses da classe. É isso que ficou evidente quando Maringá divulgou o cognome "Cidade Verde". Esse discurso procurou homogeneizar os "olhares" da cidade, tentando com isso ocultar as contradições no modelo de produção do espaço urbano maringaense. Para Citelli, "As instituições falam através dos signos fechados, monossêmicos, dos discursos de convencimento" (1995, p. 32), e neste contexto os discursos imperativos e persuasivos construídos com simplicidade textual não deixam margem para a interpretação.

\section{Do Plano Inicial a Propaganda}

A proposta de cidade jardim inicia-se na década de 1940, com a CTNP/CMNP, através de um traçado arquitetônico moderno do sítio urbano de Maringá combinado com a natureza, inspirado no modelo de Ebenezer Howard. Segundo Howard (2002), não há dualidades entre o campo e a cidade, mas sim, a combinação entre os atrativos da cidade e a beleza do campo. Neste sentido, propõe uma inovação do espaço urbano, como pode ser verificado em sua obra "Os Três Ímãs", onde apresenta uma síntese do seu ideal de cidade, ou seja, uma única cidade que fundia o espaço urbano, o campo e a cidade. Os três ímãs eram uma estratégia de planejamento regional para conter o fluxo migratório em direção aos grandes centros urbanos. No planejamento de Howard, as cidades seriam auto-organizadas e interligadas por um sistema de transporte público eficiente, e constituídas por estabelecimentos industriais e cinturões agrícolas. 
A visão ideológica de Howard foi uma tentativa de resolver os problemas de insalubridade, pobreza e poluição nas cidades. Ele buscava a combinação perfeita entre a cidade e o campo, juntando todas as vantagens de uma vida urbana cheia de oportunidades e a beleza e os prazeres do campo. Através dessa união, a migração de pessoas de cidades congestionadas se daria naturalmente para uma cidade próxima da natureza, considerada como fonte de vida, riqueza e felicidade. A indústria se deslocaria para o campo, à produção agrícola teria mercados próximos ao núcleo rural. A proposta de Howard estava pautada nos seguinte princípio:

A cidade-jardim foi construída. Sua população atingiu 32.000 habitantes. Como crescerá? Crescerá estabelecendo provavelmente por meios de poderes do Parlamento, outra cidade a uma pequena distância de sua zona "rural", de modo que a nova cidade tenha igualmente sua própria zona rural. Eu disse "estabelecendo outra cidade" e, para os fins administrativos haverá duas cidades. Mas os habitantes de uma poderão atingir a outra em poucos minutos, pois se providenciará especialmente para isso de um transporte rápido e assim o povo das duas cidades representará, na verdade uma única comunidade (2002, p. 187).

A concepção da ideia de cidade jardim de Howard visava propiciar aos homens mais liberdade através da vida comunitária, diferentemente de empreendedores, que pensam somente em rendimentos.

As ideias de Ebenezer Howard se propagaram para vários países, entre eles os Estados Unidos, a França, o Canadá e o Brasil, mas a concretização de uma cidade-jardim ocorreu somente no início do século $X X$, no próprio território inglês, em 1902, com os arquitetos Raymond Unwin e Barry Parker. Eles fizeram a primeira construção da cidade-jardim, Letchowoth, a 56 quilômetros de Londres. Possuía traçados simples, com ruas no sentido leste-oeste, seguindo a ferrovia que ligava Londres a Cambridge, cortadas por duas grandes avenidas em direção norte-sul. Essa cidade foi projetada para acolher 30.000 habitantes, com a mesma proposta de Howard, sendo constituída de grandes espaços públicos, áreas verdes em parques, praças e jardins, áreas agrícolas circundantes, habitação, comércio e indústrias separados em setores (HALL, 2000). 
Ottoni (2002), em seu livro 'Introdução: Cidade-Jardim - Formação e Percurso de uma Ideia', discute a influência de Howard em várias cidades brasileiras, como Rio de Janeiro e São Paulo, onde foram construídos bairros de alto padrão com ajardinamento nos lotes, espaços coletivos arborizados, exclusividades para construções residenciais. Esses bairros foram chamados de cidades jardim.

Para Ottoni (2002), a cidade do Rio de Janeiro recebeu influência de Alfred Agache com o projeto "A Cidade do Rio de Janeiro - Extensão Remodelação, Embelezamento". Ele propôs duas cidades-jardins, uma para a Ilha do Governador e outra para Paquetá, porém não foram concretizadas. Ao nos referirmos ao Rio de Janeiro, podemos verificar que apenas alguns loteamentos na Gávea e no Jardim Botânico basearam-se no modelo cidadejardim. Quanto aos modelos de cidades-jardim surgidos em São Paulo, temos o Jardim América, bairro de São Paulo que teve o projeto assinado por Barry Parker e Raymond Unwin, tornando-se a maior expressão de um bairro com características de uma cidade-jardim de São Paulo. Podemos destacar ainda os loteamentos no Alto da Lapa, Alto de Pinheiros, Butantã e Morumbi.

Após essa breve discussão referente às cidades jardins, não há dúvida de que o projeto de Jorge de Macedo Vieira para Maringá foi inspirado no modelo de cidade jardim, pois se tratam de um projeto que previa a estruturação espacial das zonas funcionais residencial, comercial, industrial, médico-hospitalar e administrativa previamente estabelecidas entre si por amplas avenidas com várias rótulas para amortização do tráfego, ruas com largos passeios e quatro amplos bosques no espaço urbano: Parque do Ingá, Bosque 2 (Parque dos Pioneiros), Parque das Grevíleas e Horto Florestal. Desta maneira, o planejamento urbano centra-se nos princípios da relação homem/natureza, uma vez que pressupunha uma relação harmoniosa entre o habitante e o verde, garantindo o status de cidade jardim.

Não obstante, há algumas diferenças entre a cidade-jardim de Howard e a cidade jardim de Jorge Macedo Vieira. Ebenezer Howard (2002) projeta para a cidade-jardim uma administração política autônoma e de gestão comunitária, com uma dimensão espacial delimitada por uma grande extensão de área 
verde com pequenos núcleos urbanos, visando manter a relação hamônica entre homem e natureza.

Outro ponto refere-se à distribuição dessas cidades. Para Howard, darse-ia por um grande círculo no entorno de uma cidade central para uma população de 58.000 habitantes, já as cidades do entorno seriam constituídas por populações de 30.000 habitantes. Ao todo teríamos um ciclo de seis cidades, o que resultaria em cerca 240.000 habitantes, população suficiente para desafogar os grandes centros urbanos.

Quanto às ideias desenvolvidas por Jorge Macedo Vieira, verificamos que a cidade de Maringá foi distribuída em torno de um eixo, com uma estrada de ferro cortando-a no sentido leste-oeste, sendo o seu sistema políticoadministrativo autônomo, com circulação e reprodução do capital, ao passo que, para Howard, as cidades-jardins se dariam através de um sistema administrativo de cooperativas. Percebe-se que o número ideal de habitantes não foi mantido conforme as proposições de Howard, o que sugere que os planejadores tomaram consciência de que as cidades brasileiras possuem dinâmicas e escalas de crescimento bem diferentes da população europeia. A ideia do verde e a presença maciça de amplas avenidas demonstram as modificações e a vinculação urbanística.

É neste sentido que a CTNP/CMNP, juntamente com os agentes imobiliários, utilizaram a propaganda para divulgar a imagem da nova cidade que surgia no Norte do Paraná usando expressões pitorescas, como, por exemplo: "Nova Canaã", "Eldorado", e "Terra onde se anda sobre dinheiro" (GONÇALVES, 1999, p.118). Essas expressões visavam promover a região que se desbravava.

Diante desta ideia pitoresca "terra onde se anda sobre dinheiro", a cidade foi produzida dentro da concepção de cidade-jardim que teve como objetivo atrair às preferências dos colonizadores das terras colocadas à venda. Neste sentido, a cidade foi sustentada no discurso que a criou. Discurso esse, que incrementou a imagem e a produção do espaço desde a sua formação, ou seja, Maringá surge imbuída de um forte caráter publicitário traduzindo em sua imagem de cidade verde, agradável, eficiente e com serviços disponíveis. 
Procura-se desta forma apontar no traçado da cidade e no desenho de sua planta se os sinais das cidades jardins estão evidentes, pois o projeto urbanístico contemplava, em sua teoria original, ruas arborizadas, praças, parques públicos e particulares, bem como um cinturão agrícola, nele se encontrando as ideias do imaginário de "cidade verde", "cidade ecológica" que despontou na década de 1980. É nessa década que este imaginário entra em cena no cenário nacional através do discurso ambiental. Maringá é citada pela mídia pelos seus amplos bosques naturais pelos ipês-roxos, pelos túneis verdes, pelos tapetes de flores das sibipirunas e pelas flores vermelhas do flamboiã.

É importante destacar que Jorge de Macedo Vieira, ao planejar a cidade de Maringá, deixou em sua parte central duas reservas nativas situadas no centro da cidade com o formato de pulmões humanos, ou seja, o Parque do Ingá e o Bosque 2 (Parque dos Pioneiros). Essa ideia foi baseada nos projetos de cidades-jardins de Howard. Neste contexto, Vieira ${ }^{3}$ (1986) confirma a intenção dos parques na área central de Maringá.

O projeto de Maringá, a curiosidade que se tem é que os parques que eu projetei no meio da cidade, eu projetei aqueles parques com o seguinte sentindo: de mostrar às gerações que viessem depois, quando a cidade tivesse construída, o que era Maringá antes da cidade, né? Era uma mata virgem. E de mais a mais são dois pulmões da cidade... Maringá não deve temer a poluição como o resto do mundo, ela já tem dois pulmões. (Boletim 2, Projeto Memória, 1996, p. 18).

Ao projetar a cidade Vieira tinha consigo o ideal preservacionista, ou seja, uma preocupação com a qualidade do ambiente urbano, livre de poluições, e também uma preocupação em preservar essas áreas para as gerações futuras, ideia muito semelhante ao modelo urbanístico de Howard, e é assim que surge o imaginário ecológico.

\section{A Procura de uma Imagem}

Para escrever sobre a imagem de uma cidade é necessário fazer uma espécie de investigação referente às diversas formas de representação do

\footnotetext{
${ }^{3}$ Publicado no Boletim n. 2 da Equipe Projeto Memória - 1996.
} 
espaço geográfico. É neste sentido que a imagem é constituída por representações individuais ou de grupos, pois nada é igual na cidade, e quanto maior for à cidade, maior serão a sua diversidade de formas, estruturas e funções. Neste sentido afirma Ladrière:

A apreensão de uma cidade é sempre incorreta, exploratória e
nunca acabamos de explorar uma cidade, mesmo quando há
muitos habitantes. Há os bairros, que não são familiares,
aqueles que conhecemos todas as pedras, todos os
pavimentos, todas as portas, todas as casas; mas há também
bairros longínquos que figuramos como inacessíveis que
permanecem misteriosos, um pouco inquietantes, carregados
de sombras e mistérios (1979, p. 167).

A procura de uma imagem depende da apreensão da forma como ela é passada e transmitida; é pensar a totalidade, é estabelecer ligações entre os lugares, é enxergar as contradições existentes no espaço urbano, é ver a cidade enquanto totalidade. Como afirma Ladrière, "só pode aparecer-nos em um lugar não traçado no solo, em um lugar fora da visão de perspectiva, invisível; este lugar invisível que chamamos de imaginário" (1979, p.71).

São várias as formas de avaliar a imagem da cidade, e nossa opção foi relacionar a imagem de Maringá transmitida pelo poder público e pela mídia a partir da década de 1980. Nesse período intensificaram os debates e reflexões entre os diversos segmentos da sociedade, fatos que, independentemente de suas matrizes e propósitos, apontam a necessidade de compreender a interdependência e unicidade da relação entre natureza e sociedade como caminho imprescindível para a superação dos problemas ambientais.

Durante a década de 1980 o prefeito Said Felício Ferreira incluiu em seu programa de governo projetos relacionados com paisagismo e urbanismo, e também elegeu a árvore como símbolo de preservação ambiental. Nesse período Maringá era conhecida como "Cidade Canção", título que já era considerado ultrapassado e nada trazia de benefício para a cidade. Segundo Paula (1998), Maringá necessitava de algo que remetesse à ideia de preservação ambiental, de ecologia, de qualidade de vida e beleza urbana, e acima de tudo, de um signo memorial capaz de trazer em si uma carga 
representativa de relações passadas e presentes com a natureza, e que tivesse uma linguagem universal.

Desta forma o símbolo estava presente entre os maringaenses e a ideia de natureza estava ali preservada: as amplas avenidas, ruas, praças e parques encontravam-se verdes e coloridos, a natureza preservada desde muito tempo, e assim, é utilizando a árvore como símbolo que o discurso vai sendo difundido entre a população maringaense. Esse imaginário não é algo totalmente alienante, visto que a população usufrui desse imaginário em seu favor, porém em determinados momentos ele acaba seduzindo seus moradores e visitantes, que assim se alienam em relação à realidade ali existente. É importante destacar que esse imaginário ecológico fora implantado em 1949, na época da exploração pela CTNP, e ressurgiu na década de 1980, sob a percepção do prefeito da época, o qual "lembrou" que a árvore poderia amenizar o clima urbano e também mudar a paisagem da cidade. Essa foi à estratégia usada para torná-la ambientalmente preservacionista e transformá-la em um paraíso turístico.

No ano de 1983 o prefeito Said, através da Secretaria da Cultura e Turismo do Município, lança a campanha para escolher o slogan para a "cidade verde". Nesse período a proposta foi considerada inovadora, pois reuniu os meios de comunicação e as escolas na campanha para a criação do slogan que conseguisse expressar a "consciência ecológica" da cidade de Maringá. Após ampla divulgação, o slogan vencedor foi: "Maringá: coração verde do Brasil".

Em um dos seus discursos o prefeito Said F. Ferreira (1984) destaca a valorização das qualidades geográficas e humanas da cidade de Maringá e ressalta que:

A natureza é obra do Criador. O Homem, obra prima do universo, dotado de liberdade e razão, podendo aprimorar ou destruir a bela Natureza.

Com um realce de vista, a pessoa sensível percebe fácil atuação do Homem na transformação do meio ambiente e na construção de novas realidades.

Maringá é obra do engenho humano, que se aliou aos seus recursos naturais para um porvir risonho. A verdade é que seu destino é certo e seguro. Dotado de terras especiais e em 
localização ideal, o homem plantou na mata virgem a bela cidade.

Seus atrativos, sua beleza e encantos, foram multiplicados pela criatividade humana... (PMM,1984).

$\mathrm{Na}$ transcrição do discurso do prefeito verificamos que as palavras "Criador", "Homem" e "Natureza" aparecem com as iniciais maiúsculas, sendo todas colocadas no mesmo nível. Para o prefeito, tanto o Criador como o homem e a natureza "criaram" para que a natureza vivesse em harmonia, ou seja, no "paraíso" que é Maringá. Na realidade, o discurso do prefeito está reafirmando a ideia da CTNP/CMNP na ótica do prefeito e da Companhia. Os homens que "plantaram" a cidade no meio da floresta são tão criadores quanto - Criador. Para Paula (1998), "o discurso é diretamente dirigido ao "estrangeiro", àquele que, sendo de outro espaço fora de Maringá, reconheça os encantos que a cidade tem a oferecer e também decida por nela investir" (p.188). Levando em consideração a ideia do discurso, percebemos que é um convite ao investimento empresarial no município, pelas oportunidades que são oferecidas.

A partir deste momento estão lançadas pela população as bases para o marketing de Maringá como "cidade verde" e seu imaginário. Neste sentido afirma Baczko:

A influência dos imaginários sociais sobre as mentalidades depende em larga medida da difusão destes e, por conseguinte, dos meios que asseguram tal difusão. Para garantir a dominação simbólica, é de importância do capital o controle dos meios, que correspondem a outros tantos instrumentos de persuasão, pressão e inculcação de valores e crenças. É assim, que qualquer poder procura desempenhar um papel privilegiado na emissão dos discursos que veiculam os imaginários sociais, do mesmo modo que tenta conservar certo controle sobre os circuitos de difusão (1984, p. 313).

A ideia apresentada por Bronislaw Baczo na citação anterior vem ao encontro da proposta lançada pelo município de Maringá, pois a construção simbólica de "cidade ecológica" ocorreu em um espaço social, ou seja, a escola, um dos meios mais eficazes para divulgar a ideia de preservação ambiental. Não obstante, esse espaço serviu de estratégias e interesses do 
poder político, contribuindo, segundo Paula (1998), para "escamotear a ideia de desmatamento desmedido promovido pela (re)ocupação do município de Maringá, o qual, mesmo tendo sido idealizado com um cinturão verde, não foi capaz de proteger a cidade da poluição das queimadas na época..." (p.154).

A partir da década de 1980 se intensificam as propagandas desenvolvidas pela Prefeitura do Município de Maringá através de jornais locais, por meio de cartazes e fôlderes distribuídos nos hotéis e agências de viagens que apresentavam a cidade como um lugar paradisíaco. Toda essa propaganda visava ao marketing da "cidade verde".

Neste contexto, algumas propagandas foram desenvolvidas pela Prefeitura do Município de Maringá a partir da década de 1980. Um dos primeiros fôlderes a ser lançado tinha o slogan "Viver Maringá". Ele traz a imagem do Parque do Ingá, fotos de jardins, praças, templos religiosos e ruas amplamente arborizadas e o Horto Florestal; porém no interior desse fôlder duas imagens estão em destaque: a praça do monumento do desbravador e uma imagem da cidade com a seguinte frase "Conheça Maringá, A Cidade Verde". Este fôlder apresenta a cidade de Maringá cercada pelos seus muros "naturais", colorida e com suas ruas arborizadas, dando a ideia de uma cidade verde e planejada e de qualidade de vida para seus habitantes.

Com o término da gestão do prefeito Said Ferreira, seu sucessor, 0 prefeito Ricardo Barros, apresenta o próximo fôlder com o slogan "Maringá a Opção Pelo Melhor/Option For The Best”. Este fôlder transmite a ideia de que a cidade e o campo estão muito próximos, pois o espaço que os separa é apenas o da plantação de soja. O que nos chama a atenção nesse fôlder são as informações direcionadas em dois idiomas: inglês e português. Na contracapa do fôlder há o seguinte texto:

Maringá, canção que virou cidade moderna, arrojada, de contrastes. Extensas áreas verdes convivem em perfeita harmonia com o conforto e o planejamento racional, que proporcionam qualidade de vida acima da média.

Cidade cosmopolita, mas que ainda mantém suas extensas fazendas, reservas florestais e sítios que são um refúgio ao alcance da mão. $O$ burburinho do progresso $e$ do desenvolvimento acelerado são abafados pelo verde da paisagem. As fábricas fundem-se com os campos. A paisagem bucólica dos arredores da cidade é um contraposto à agitação 
de 350 mil pessoas, que compram, trabalham e fazem de Maringá um dos centros regionais mais importantes do país. Maringá é assim. Ao mesmo tempo uma usina do progresso e um oásis de tranquilidade (Folder PMM, 1990).

Ao analisar a citação anterior verificamos que o discurso apresentado é dirigido ao público visitante, e o convite a usufruir de um paraíso bucólico nos remete a uma ideia tentadora, pois coexistem o progresso e a tranquilidade das áreas verdes. Outro ponto a destacar é que, ao ler o texto, é levado a crer na existência harmoniosa entre as fábricas e as paisagens bucólicas. Aqui o verde está associado à ideia de progresso. No interior do fôlder são apresentadas informações de agências turísticas, bancárias, de transporte aéreo e rodoviário, locadoras de automóveis, principais pontos de táxi, cinemas, shoppings, pronto socorro, relações de restaurantes e casas noturnas, etc. Toda a informação contida no fôlder permite ao leitor formar uma imagem da cidade de Maringá, em que se harmonizam o concreto das edificações e o verde, oferecendo 0 conforto e as tecnologias disponíveis e garantindo tranquilidade, beleza e segurança aos seus visitantes.

A imagem publicitária utilizada pelo Poder Público foi muito forte e dominadora, e transmitia aos cidadãos a ideia de uma cidade planejada e sem problemas. Nela se utilizam imagens belas, dando a noção de um paraíso que sobreviveu acompanhado do progresso. A "cidade verde" é o paraíso perfeito para as férias e o lugar apropriado para a aquisição de propriedades longe dos grandes centros poluidores.

A Prefeitura Municipal de Maringá, através da RCA- Vídeos produções, elaborou o vídeo chamado "Maringá, 50 anos - Um Mergulho no Paraíso Verde". A sequência de imagens das ruas e avenidas em movimento apresentada no vídeo nos dá a sensação de velocidade. À medida que as imagens apresentam os parques da cidade, o movimento se torna mais lento, conduzindo o espectador a uma ideia de tranquilidade. A imagem transmitida é de uma cidade preservacionista e ecológica, e por trás dela há uma verdadeira apologia da cidade verde. As transformações ocorridas no espaço urbano maringaense aparecem de forma tênue, como representantes do desenvolvimento econômico da região e da integração com outras áreas do 
país. Tudo passa a ideia de um verdadeiro paraíso, onde o verde é o integrador do progresso e da preservação ambiental.

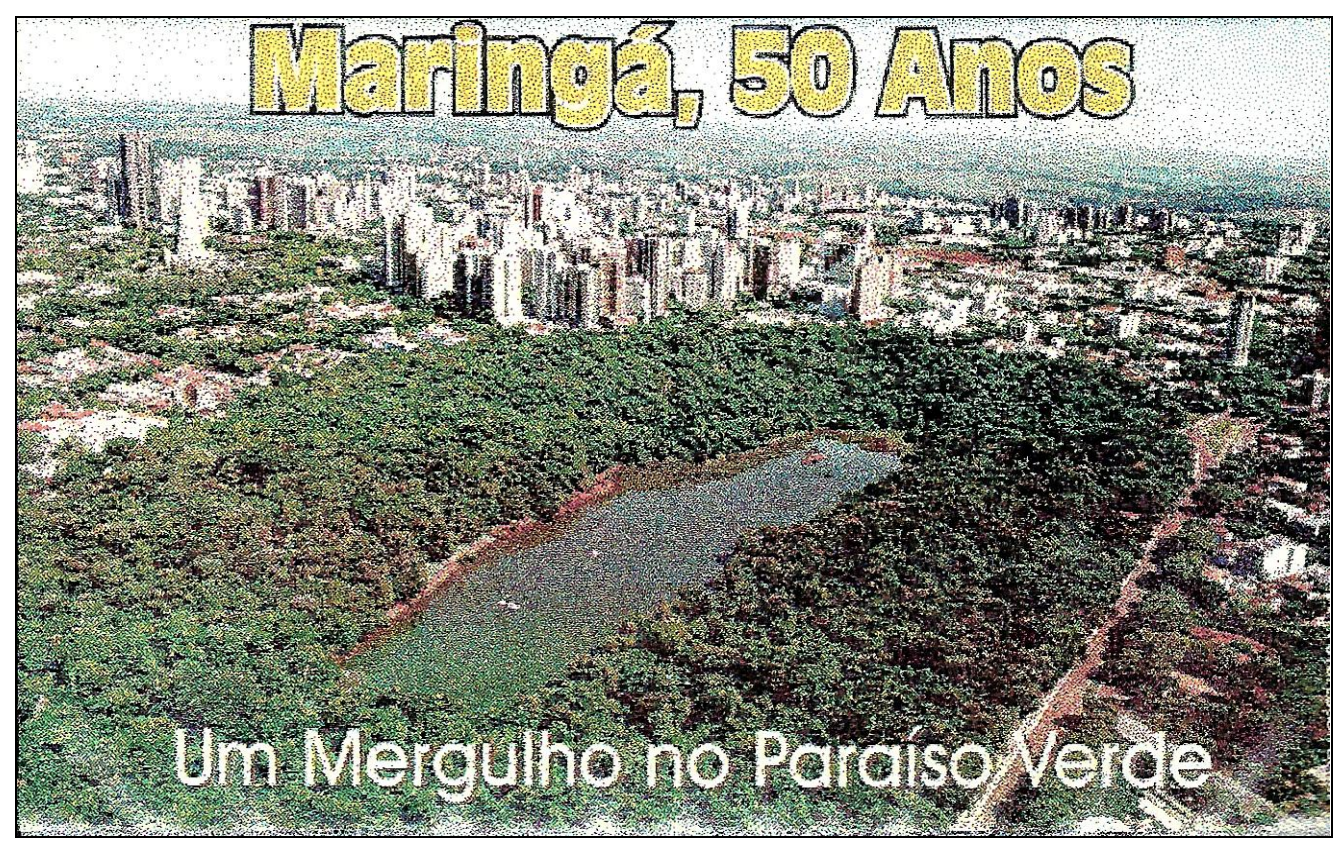

Figura 04: Capa do CD do vídeo - Maringá 50 anos

Fonte: Prefeitura Municipal de Maringá.

A imagem publicitária nunca esteve dissociada das políticas para o Norte do Paraná, e no final da década de 1990 a campanha publicitária sobre Maringá intensificou-se, gerando um planejamento estratégico e fazendo com que os discursos publicitários se tornassem um modelo para o planejamento empresarial, no qual as cidades estão submetidas às condições e desafios de uma empresa. Os governos neoliberais e os grandes empresários veem a cidade como se fosse uma empresa, e nesse sentido é necessário que regras sejam estabelecidas ao discurso veiculado na propaganda.

No ano de 1999 Maringá foi comparada a Dallas (EUA) em uma reportagem da revista Veja:

[...] um desejo mal disfarçado dos moradores dessa espécie de capital do noroeste do Paraná: ser uma extensão do Texas ou da Califórnia no Brasil. Maringá não tem o interesse em imitar o destino das grandes capitais brasileiras. Maringá está mais perto do Texas que do Brasil. É o que mostram os 
índices sócio-econômicos... (LIMA. M. In. REVISTA VEJA, N. 20, 1999, p. 16).

Lima (1999), ao usar a imagem americana como desejo dos moradores, mostra o discurso construído, ou seja, um consenso entre os cidadãos que depreciam a sua própria cultura, para os quais o que importa é o sucesso da cidade como empresa, em que não se admitem conflitos. É importante destacar que os moradores ficam deslumbrados por terem a sua cidade comparada a grandes centros urbanos, pois as propagandas estimulam o orgulho de ser maringaense e viver em uma cidade verde. Por outro lado há moradores que acreditam naquilo que dizem as reportagens e não contestam os fatos inverídicos existentes nas entrelinhas, como o verificado no seguinte trecho da reportagem “... não espere encontrar cinemas e teatros por todo o lado. $\mathrm{Na}$ hora da diversão, são outras atrações que fazem à festa dos habitantes. Existem três grandes eventos na agenda anual da cidade: um rodeio, uma feira agrícola e a escolha da Garota Country ... (LIMA, 1999, p. 16).

Neste contexto, a reportagem não menciona em nenhum momento a grande comunidade japonesa, com sua etnia, tradição cultural e com seus espaços construídos. Desta forma concluímos que há um esquecimento e o que importa é a imagem texana, uma vez que a oriental é totalmente contrária ao discurso.

Por esta ótica, Maringá torna-se uma mercadoria a ser vendida e o marketing urbano desempenha um papel importante, pois outras cidades também estão à venda. Para Vainer (2000), ao "vender" uma cidade é preciso saber o que se põe à venda que pode ir além de espaços de convenções até segurança. No caso de Maringá, o que se vende é a imagem da cidade verde (figura 04), de centro regional, de qualidade de vida, de segurança, sucesso empresarial, da circulação de mercadoria e do Novo Centro ${ }^{4}$.

\footnotetext{
${ }^{4} \mathrm{O}$ nome Novo Centro não é o mais adequado para explicar as transformações desta área, pois não se trata da criação de um centro novo, mas da incorporação desta região vizinha ao centro tradicional. Negri (1997) e Negri e Mendes (1998), fazendo uma critica ao nome escolhido do projeto, chamam a área de "falso Novo Centro". Os autores questionam a ideia de criação de um novo centro, e consideram a ideia falsa, pois, para eles, o que está ocorrendo e a incorporação da área pelo pela expansão do centro tradicional.
} 


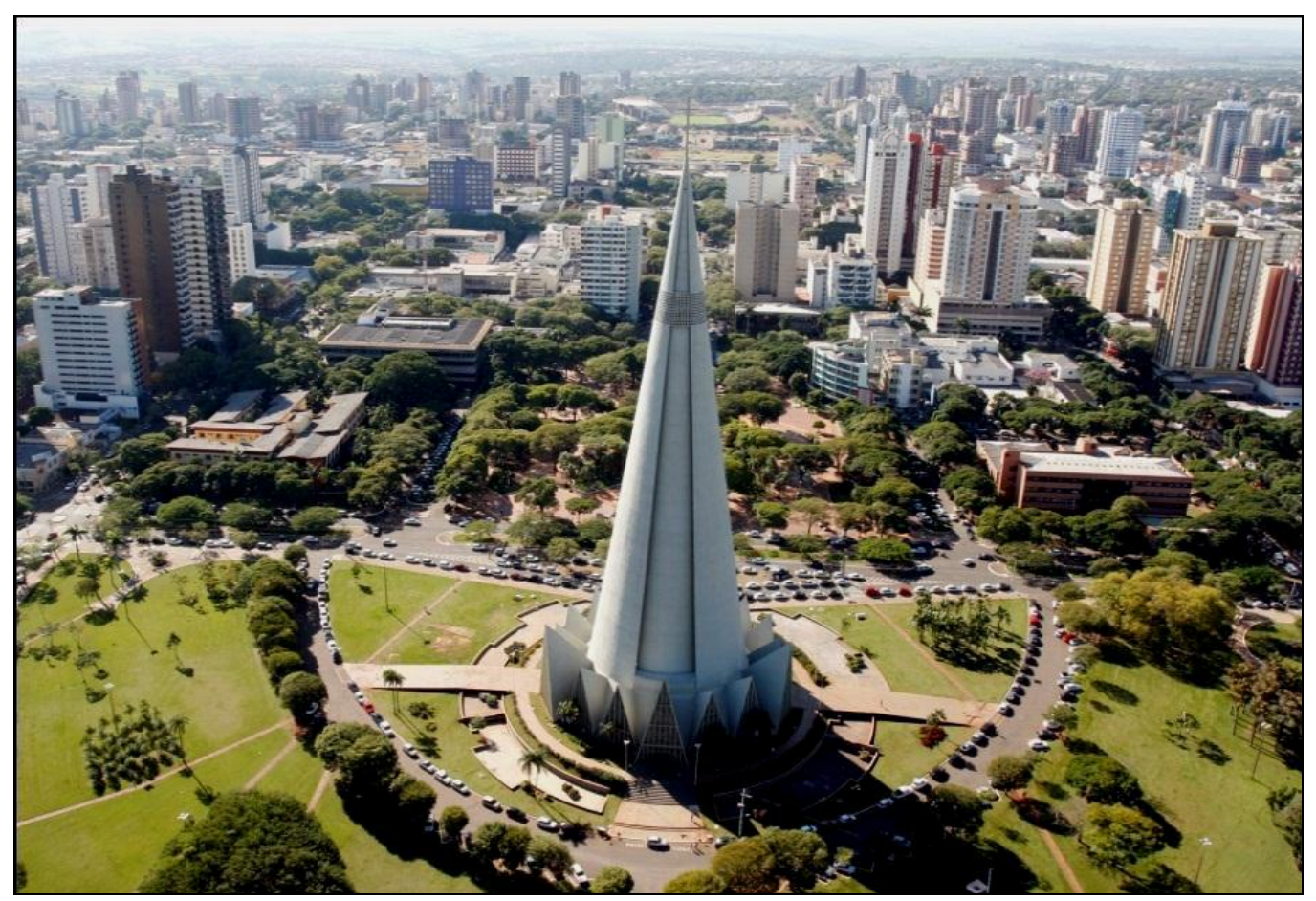

Figura 04 - Basílica Menor de Nossa Senhora da Glória, Maringá.

Fonte: PREFEITURA MUNICIPAL DE MARINGÁ, Pontos turísticos, (2010).

Essa imagem é repetida nos órgãos públicos, como pode ser verificado na transcrição abaixo de Kiouranis \& Teixeira.

O vertiginoso progresso de Maringá acontece harmoniosamente sem perder suas características de cidade projetada, onde a consciência pela preservação da natureza impõe como se pode notar pela sua farta arborização que proporciona um festival de cores todos os meses do ano. Nesta cidade moderna e arrojada extensas áreas verdes convivem em perfeita harmonia com o conforto e 0 planejamento racional que proporcionaram qualidade de vida acima da média (KIOURANIS \& TEIXEIRA. 2000, p. 5).

Para as autoras, os órgãos públicos procuram passar uma imagem de convencimento, positiva e atraente para os grandes investidores, ou seja, a imagem de cidade sem problemas socioambientais.

Anos depois, em 2005, chama-nos a atenção uma outra reportagem, intitulada "Do Velho Oeste ao Paraíso" veiculada em nível nacional pela Revista Época. Vejamos na transcrição a seguir da imagem de cidade verde: 
Viver num lugar tranquilo, onde se sai à noite sem medo, as crianças brincam na rua e podem ir à escola de ônibus, é um sonho de toda a família de cidade grande. Refúgios assim ainda existem no Brasil. Uma pesquisa inédita feita pelo Instituto de Pesquisa Econômica Aplicada (Ipea), que Época divulga com exclusividade, mapeou o país à procura das cidades mais seguras e também das mais violentas. Cruzando dados oficiais, os pesquisadores criaram um índice que mede o risco de uma pessoa a ser assassinada nos municípios com mais de 300 mil habitantes. Maringá, no rico noroeste do Paraná, lidera o ranking de tranquilidade. Serra, nos arredores de Vitória, é a campeã de violência (CLEMENTE, I. In REVISTA ÉPOCA, 04/04/2005, p. 75-77).

texto da reportagem apresenta a ideia de competitividade que se encontra presente entre as cidades com mais de 300 mil habitantes, mostrando um ranking entre elas. No caso de Maringá, esses índices justificam-se pela inexistência de favelas, já que a população mais carente reside nos municípios periféricos, como Paiçandu e Sarandi, cidades conurbadas a Maringá. Para Vainer (2000), no planejamento estratégico admite-se apenas uma demanda solvável, os pobres estão do lado de fora, porque compromete a atratividade da cidade tanto do ponto de vista do concreto quanto da imagem que é transmitida. Na mesma reportagem de Clemente (2005, p. 77), o autor evidencia a ordem desejada, através de denúncias.

[...] a Prefeitura não autoriza construções em locais sem infraestrutura completa, o que inibe a formação das favelas. Ao menor sinal de um aglomerado, a população denuncia e a prefeitura age. A sociedade civil, por sua vez, cobra o tempo todo. Semanalmente empresários se reúnem para discutir as carências de Maringá, procurando definir propostas para encaminhar ao poder público contra a violência (CLEMENTE, I. In REVISTA ÉPOCA, 04/04/2005, p.77).

Pela citação acima se pode verificar que os empresários decidem sobre a cidade, a sociedade civil tem o papel de denunciar e a prefeitura age. Em Maringá o marketing "cidade verde", "cidade ecológica", é mantido pelo poder público, por empresários do ramo imobiliário e pela própria população. "Maringá, ao contrário, parece um pedaço do paraíso, quando comparada à maior parte das cidades brasileiras", afirma Clemente (2005).

Dessa forma, é compreensível a aceitação do discurso oficial do poder público sobre a sua arborização, o qual passa a ser reproduzido pela 
população. O slogan de "cidade verde" traduz a representação social da harmonia socioambiental em seu espaço urbano, na medida em que esta é favorecida pela estrutura espacial da cidade, que apresenta amplas ruas, avenidas, praças e parques arborizados.

\section{CONSIDERAÇÕES FINAIS}

Ao longo deste artigo apontamos uma discussão referente à imagem da cidade verde, transmitida pelos políticos, empresários e empreendedores imobiliários e pela ação da mídia sobre o ideário construído. Diante das ponderações apresentadas percebemos o belo, o atraente modelo de cidade ideal com suas áreas verdes em plena harmonia com a natureza preservada, com suas belas praças, seus magníficos parques, com os lindos ipês floridos e suas amplas avenidas e ruas arborizadas. Passa-se a imagem de que tudo é maravilhoso em Maringá e de que a cidade caminha dentro da modernidade em plena harmonia, em que o homem e a natureza vivem em sincronia, embora se apresentem alguns problemas ambientais que não chegam a comprometer totalmente a ideologia do verde.

Ao referimos a política ambiental, percebemos que ela é muito avançada no que se refere à preservação, recuperação e manutenção de recursos naturais existentes no município, porém, podemos perceber que nem sempre essas leis são executadas na prática pelo poder público maringaense.

\section{7-REFERÊNCIAS}

BACZKO Bronislaw. Imaginação Social. Enciclopédia Einaudi. Vol. 5 anthropos-homem. Porto Imprensa Nacional/ Casa da Moeda, 1994.

BAUDRILLARD, Jean. A Sociedade do Consumo. Lisboa. Edições 70. 1995.

BRASIL, Constituição da República Federativa do Brasil. Oliveira Juarez (org). São Paulo. Saraiva, 1998. Série legislação brasileira.

CARLOS, Ana Fani Alessandri. O Meio Ambiente Urbano e o Discurso Ecológico. In. Revista do Departamento de Geografia da USP. N.8. Faculdade de Filosofia, Letras e Ciências Humanas, 1994. 
CARVALHO, Luiz D. M; MENDES César Miranda. Considerações Sobre a Evolução da Geografia Urbana no Brasil e no Paraná. Boletim de Geografia, 17, p. 29-59. Maringá, DGE/UEM, 1999.

CARVALHO, Luiz Domingos Moreno. O Posicionamento e o Traçado Urbano de Algumas Cidades Implantadas pela Companhia de Terras Norte do Paraná e a Sucessora Companhia Melhoramentos Norte do Paraná. Dissertação (mestrado em Geografia), Universidade Estadual de Maringá. Maringá, 2000.

CERTEAU, Michel de. A Invenção do Cotidiano - artes de fazer. Petrópolis. Vozes, 1994.

CLEMENTE, Isabel. Do Velho Oeste ao Paraíso. In. Revista Época. São Paulo, N.259, p.75-77, 4 abr. 1996.

CITELLI, Adilson. Linguagem e Persuasão. São Paulo. Ática. 1995. COMPANHIA MELHORAMENTOS NORTE DO PARANÁ - CMNP. Colonização e Desenvolvimento do Norte do Paraná. (s.e), 1975.

ESTRADA, Jorge F. Duque. Terra Crua. Curitiba, 1996.

GARCIA, Júlio César. Maringá Verde?o desafio ambiental da gestão das cidades. Maringá. Eduem, 2006.

GONÇALVES, José Henrique Rollo. Quando a Imagem Publicitária Vira Evidência Factual: versões e reversões do Norte (Novo) do Paraná- 1930/1970. In. DIAS Reginaldo Benedito; GONÇALVES, José Henrique Rollo (org). Maringá e o Norte do Paraná. Maringá. Eduem. 1999.

HALL, Peter. Cidades do Amanhã. São Paulo. Perspectiva, 2000.

HARVEY, David. A Condição Pós Moderna. São Paulo. Loyola, 1994

HEIDECKE, Sandra Cristina. Um Projeto Ambicioso em Busca da Identidade: Shopping Royal Plaza de Londrina-PR. Dissertação de Mestrado, Maringá: DGE. Maringá: UEM, 2001.

HOWARD, Ebenezer. Cidades-Jardins de Amanhã. São Paulo. AnnablumeHucitec, 2002.

KIOURANIS, Neide Maria; Texeira, Rosangela de Oliveira. Maringá "Cidade Ecológica”. Revista Teia. Dez. 2000. Disponível em: <www.pea.br/teia/2000dez/2.html>. Acesso: 30 de maio 2006.

LADRIÈRE, Jean. Vida Social e Destinação. São Paulo. Convívio. 1979.

LEFEBVRE, Henri. A Vida Cotidiana no Mundo Moderno. São Paulo. Ática. 1991 
LIMA, Mauricio. Dallas no Paraná. In. Revista Veja. N. 20, São Paulo, 1999.

NEGRI, Silvio Moisés. A Expansão da Periferia na Região Metropolitana de Maringá: a cidade de Paiçandu. In: MENDES C. M; SCHMIDT L. P. (Orgs.). A Dinâmica do Espaço Urbano-Regional: pesquisas do norte central paranaense. Guarapuava. UNICENTRO, 2006.

OTTONI, D. Araújo Benedicto. Introdução: Cidade Jardim. Formação e Percurso de uma Idéia. São Paulo. Annablume-Hucitec, 2002.

PAULA, Zueleide Casagrande de. Maringá: o coração verde do Brasil? Dissertação (Mestrado em História) - Universidade Estadual Paulista UNESP. Assis, 1998.

REGO, Renato Leão. O Desenho Urbano de Maringá e a Idéia de CidadeJardim. Acta Scientiarum, Maringá, v. 23 n‥ 6, p. 1559-1577, 2001.

RIBEIRO, Ana C. T. GARCIA, Fernanda S. City Marketing: a nova fase da gestão da cidade no final do século. In. REIS, E.; ALMEIDA, M. H. T.; FRY, P (org). Política e Cultura: visões do passado e Perspectivas Contemporâneas. São Paulo. Hucitec/ANPOCS, 1996.

SANTOS, Milton. O Espaço do Cidadão. São Paulo. Nobel, 1996.

UNWIN, R. La Practica del Urbanismo: uma introducción al arte de proyectar ciudades e bairros. Barcelona, GG. 1984. 